\title{
A Rehabilitation-Based Multidisciplinary Care Model Reduces Hip Fracture Mortality in Older Adults
}

\author{
Chun-Feng Huang $\mathbb{1}^{1,2}$ \\ Po-Jung Pan $^{3}$ \\ Yi-Hung Chiang ${ }^{4}$ \\ Shung-Haur Yang ${ }^{5}$
}

'Department of Family Medicine, National Yang Ming Chiao Tung University Hospital, Yilan, Taiwan (R.O.C); ${ }^{2}$ Department of Leisure Services Management, Chaoyang University of Technology, Taichung, Taiwan (R.O.C); ${ }^{3}$ Department of Physical Medicine and Rehabilitation, National Yang Ming Chiao Tung University Hospital, Yilan, Taiwan (R.O. C); ${ }^{4}$ Department of Orthopedics, National Yang Ming Chiao Tung University Hospital, Yilan, Taiwan (R.O.C); ${ }^{5}$ Department of Surgery, National Yang Ming Chiao Tung University Hospital, Yilan, Taiwan (R.O.C)
Correspondence: Chun-Feng Huang Department of Family Medicine, National Yang Ming Chiao Tung University

Hospital, No. 152, Xinmin Road, Yilan,

Yilan County, 26042, Taiwan (R.O.C)

Tel +886-3-932-5192

Fax +886-3-9372119

Email cfhuang.ymuh@gmail.com
Purpose: In older adults, the one-year mortality rate after experiencing a hip fracture ranges between $8 \%$ and $36 \%$. The purpose of this study was to look at the efficacy of rehabilitationbased multidisciplinary care for older individuals who had hip fractures.

Patients and Methods: The study included 185 people (aged 65 and over) with a history of hip fracture surgery between February 2014 and March 2017. A survey was conducted one month and six months following the operation to assess the recovery of 93 individuals who were part of a rehabilitation-based multidisciplinary care program and 92 patients who were getting standard therapy with surgery and unsupervised physical therapy.

Results: Physical activity, gait, balance evaluation, and depression scale ratings all had statistical significance $(P<0.05)$ after participants received rehabilitation-based care services from multidisciplinary medical professionals. Furthermore, the refracture and one-year mortality rates in this rehabilitation-based multidisciplinary care model were lower than in the groups getting standard therapy.

Conclusion: The research indicates the efficacy of a multidisciplinary rehabilitation strategy provided by a collaborative medical team to older individuals with hip fractures.

Keywords: hip fracture, multidisciplinary care, osteoporosis, rehabilitation

\section{Introduction}

Every three seconds, one osteoporotic fracture occurs worldwide. The spine, hip, wrist, and humerus are the most prevalent sites for osteoporotic fractures. ${ }^{1}$ The risk of fracture rises with age due to bone mass loss and an increased risk of falls. After the age of 50, one-half of women and one-fifth of men experience a fracture. ${ }^{2}$ Refractures occur in nearly half of all patients with osteoporotic fractures. ${ }^{3,4}$ Hip fracture is one of the most serious complications of aging, and it is the seventh leading cause of death in older adults. ${ }^{5,6}$ As a result, patients suffering from hip fractures must take extra care to avoid complications including refractures.

Taiwan has been one of the world's fastest aging regions. ${ }^{4}$ Aging causes decreased muscular strength, and a significant decline in balance and gait function; when these factors are combined with bone mass loss due to osteoporosis, the risk of hip fracture from low energy trauma increases even more. ${ }^{7}$ As a result, the number of individuals in Taiwan with fractures increased by $10 \%$ in five years, and more than 675,000 people seek medical attention each year as a result of a fracture. ${ }^{8}$ 
Hip fractures in older individuals have become a major public health concern, with the government incurring significant expenses to address the issue.

In Taiwan, four types of fracture treatment approaches for older persons are now used. The first and most prevalent approach is based on traditional care, in which patients with fractures are admitted to the hospital and treated by an orthopedist or orthopedic team, followed by unsupervised physical therapy. The second model is an enhanced conventional paradigm in which geriatric experts and orthopedists collaborate to create therapeutic approaches. Orthopedists offer pre-surgery treatment in the third model, while geriatric specialists provide postsurgery care. Patients with fractures are allocated to a specific fracture ward for older individuals in the fourth model, and care is given by orthopedists who specialize in working with older persons.

Even though different programs, such as the fracture liaison service, have been shown to minimize postoperative mortality and complications in hip fracture patients, a cohesive treatment approach tailored to Asian older hip fracture patients has yet to be developed. ${ }^{9}$ As a result, we created the Integrated Hip Fracture and Osteoporosis Rehabilitation Program for the Elderly (i-HOPE), a multidisciplinary care paradigm for older patients with hip fractures that emphasizes rehabilitation, osteoporosis therapy, and self-care techniques for improving home settings. The purpose of this study was to assess the risk of falling, the likelihood of refracture, general physical function, and mortality rate in older individuals with hip fractures who received the i-HOPE intervention.

\section{Materials and Methods}

\section{Participants in the Study}

This retrospective chart study looked at patients who had hip fracture surgery. For eligibility, all patients have been screened. From February 2014 to March 2017, a total of 185 patient records were reviewed. This research comprised individuals over the age of 65 who had no traumatic event and consented to surgery. Figure 1 depicts the enrollment criteria.

\section{Protocol on Intervention}

Patients were separated into two groups based on whether they were engaged in the i-HOPE program or were receiving traditional care that included surgery and unsupervised physical therapy. During the hospitalization of i-HOPE program participants, multidisciplinary specialists were engaged to assess the patient and provide a comprehensive proposal immediately after the operation. The physical therapist began a tailored limb strengthening exercise program and walker-assisted ambulation training at the patient's bedside. The occupational therapist advised each patient and their family on walking aid equipment and home environment changes. The fall prevention technique was emphasized once again during the one-month post-surgery home visit and out-patient department visit six months later, when the geriatric depression scale (GDS), activities of daily living (ADL), instrumental ADL, Elderly Mobility Scale (EMS), and Tinetti Performance Oriented Mobility Assessment (POMA) were used by geriatric specialists to assess each patient's emotional state, physical activity, gait, and balance abilities. ${ }^{10-13}$ Furthermore, the medication adherence rate was calculated by summing the number of days the osteoporosis medicine was administered and dividing by the duration of a year.

\section{Ethics}

This study was approved by the Institutional Review Board (IRB) of the National Yang-Ming University Hospital (YMUH2016A027) in accordance with the Declaration of Helsinki. The study involves no prospectively collected data so there is no access to patients or opportunity to seek informed consent. A waiver of consent was approved by IRB as re-contacting this number of patients to obtain informed consent would be impracticable. The study is no greater than minimal risk and will have no direct impact on patient's rights, confidentiality, or clinical care.

\section{Statistical Analysis}

To describe the fundamental features, descriptive statistics were utilized. Formal statistical analyses were carried out using IBM SPSS Statistics for Windows, version 22 (IBM Corp., Armonk, N.Y., USA). The difference in response variable change between subjects before and after the i-HOPE program was compared. A generic linear model with adjustments for age, gender, body mass index (BMI), and baseline value for medical conditions was used to evaluate differences between patients who received multidisciplinary care plans and those who did not. The minimum total sample size in this study is 128 , with at least 64 subjects for each independent variable, for an effect size of $\mathrm{d}=0.5$, power $=0.8$, and $\alpha=0.05$. 


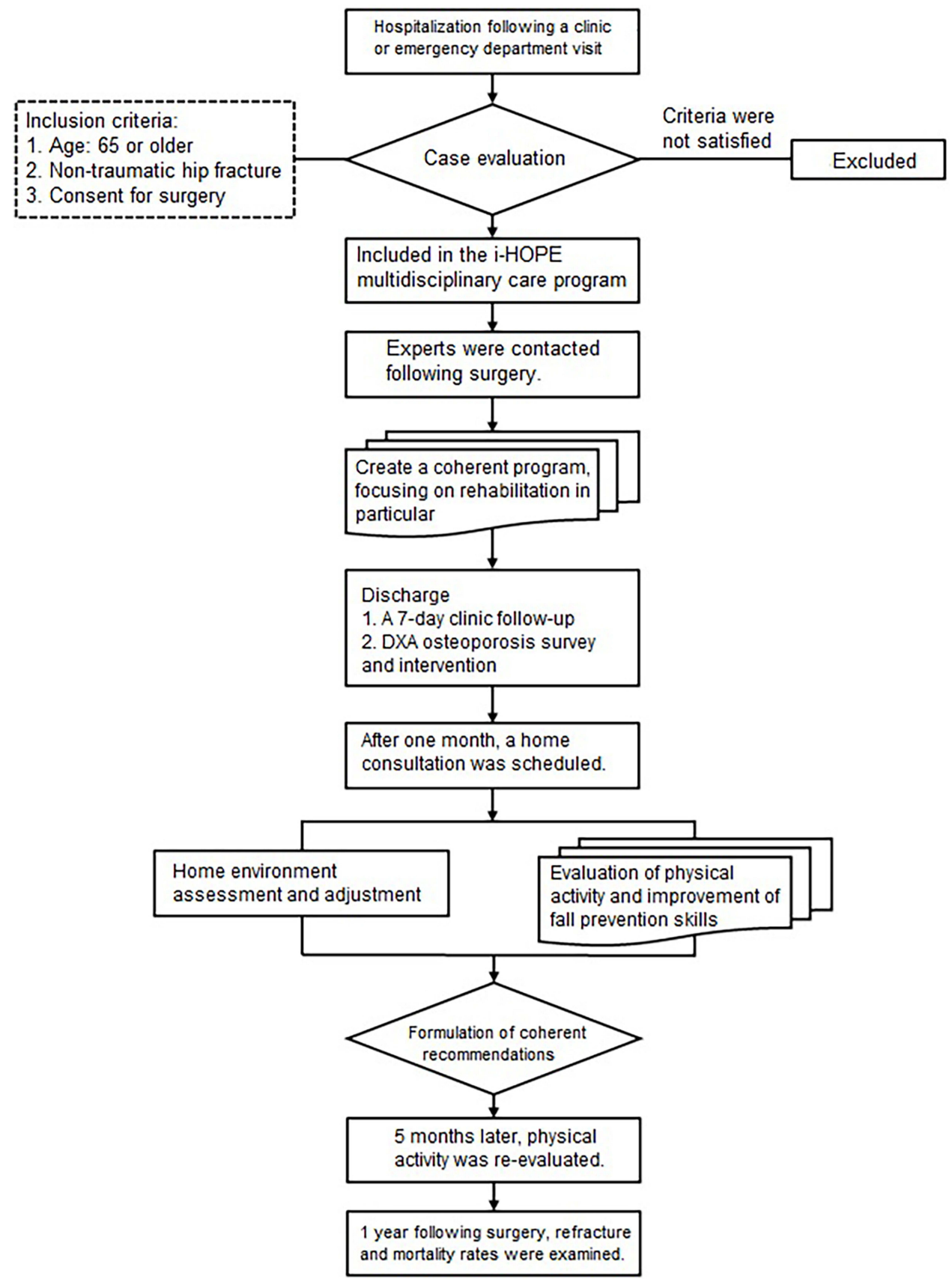

Figure I Enrollment in the i-HOPE program flowchart.

\section{Results}

When the patients' baseline characteristics were examined, there was no difference in sex, age, BMI, or medical issues between the individuals receiving multidisciplinary care $(n=93)$ and the control groups receiving traditional care $(\mathrm{n}=92)$ (Table 1).

The average age and standard deviation (SD) of patients were 72.9 (6.1) years. Individuals in the i-HOPE program began one month of rehabilitation after the surgery and then continued to actively adjust for a total of six months of rehabilitation over the next five months. When compared to 1-month after surgery, patients who received the following 5-month integrative care services from a multidisciplinary medical team improved significantly in GDS $(0.7 \pm 1.0$ versus $0.9 \pm 1.3)$, ADL (66.6 \pm 27.9 versus $42.3 \pm 27.8)$, instrumental ADL (2.2 \pm 2.4 versus $1.2 \pm 1.6$ ), physical activity (EMS, 12.8 
Table I Characteristics and Outcomes of Individuals Receiving Multidisciplinary Care (I-HOPE) versus the Control Group

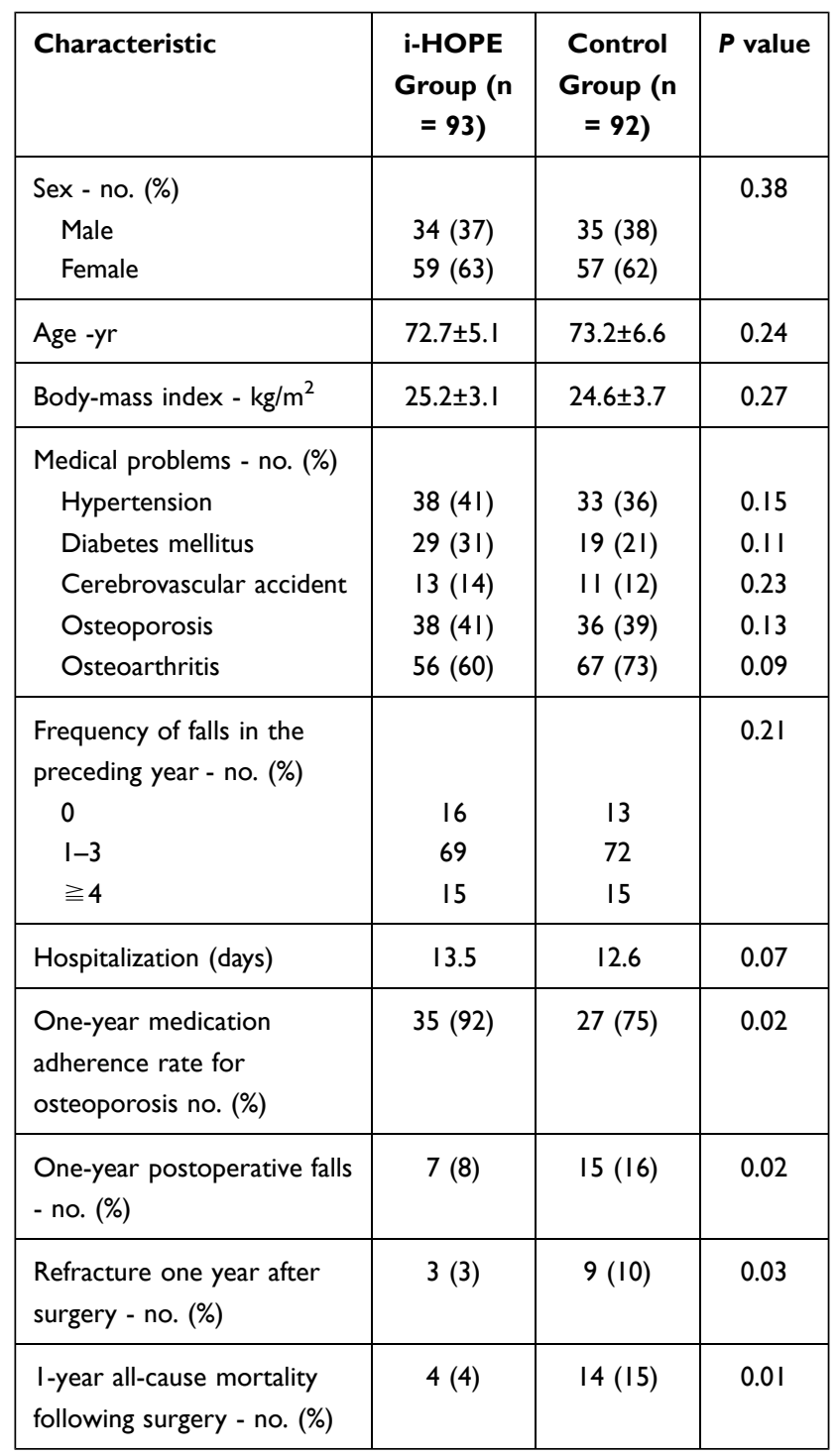

Note: Data are presented as mean $\pm S D$ or number (percentage).

Abbreviation: i-HOPE, the Integrated Hip Fracture and Osteoporosis Rehabilitation Program for the Elderly.

\pm 6.0 versus $8.1 \pm 4.7$ ), gait, and balance abilities (POMA, 19.1 \pm 9.0 versus $10.6 \pm 7.2$ ) (Table 2 ). The incidence of repeated falls, recurrent fractures, and one-year mortality rate were $8 \%, 3 \%$, and $4 \%$, respectively, substantially lower than the control group receiving traditional treatment (Table 1).

\section{Discussion}

Taiwan has one of the highest rates of hip fractures in the Asia-Pacific region and worldwide. ${ }^{14-16}$ In Taiwan, the mortality rate for patients with a hip fracture one year after surgery is $14.6 \%$ (18\% for men and $11.2 \%$ for women). ${ }^{17}$ Patients with osteoporosis who have already
Table 2 Changes in Evaluation Scales for Patients Receiving Multidisciplinary Care Following Hip Surgery

\begin{tabular}{|l|c|c|c|}
\hline $\begin{array}{l}\text { Evaluation } \\
\text { Scale }\end{array}$ & $\begin{array}{c}\text { After-Surgery } \\
\text { Period }\end{array}$ & $\begin{array}{c}\text { Mean } \\
\mathbf{I S D}\end{array}$ & P value \\
\hline GDS & $\begin{array}{l}\text { I month } \\
6 \text { months }\end{array}$ & $\begin{array}{c}0.9 \pm 1.3 \\
0.7 \pm 1.0\end{array}$ & 0.021 \\
\hline ADL & I month & $42.3 \pm 27.8$ & 0.018 \\
& 6 months & $66.6 \pm 27.9$ & \\
\hline IADL & I month & $1.2 \pm 1.6$ & 0.013 \\
& 6 months & $2.2 \pm 2.4$ & \\
\hline EMS & I month & $8.1 \pm 4.7$ & 0.015 \\
& 6 months & $12.8 \pm 6.0$ & \\
\hline POMA & $\begin{array}{l}\text { I month } \\
6 \text { months }\end{array}$ & $10.6 \pm 7.2$ & 0.011 \\
\hline
\end{tabular}

Abbreviations: ADL, activities of daily living; EMS, Elderly Mobility Scale; GDS, Geriatric Depression Scale; IADL, instrumental activities of daily living; POMA, Tinetti Performance Oriented Mobility Assessment.

had hip fractures are two to four times more likely to fracture than those who have not. ${ }^{18}$ However, prior research has revealed that only around one-third of individuals with fragility fractures receive a thorough examination. ${ }^{19-21}$ In Taiwan, only around one-quarter of women with hip fractures have their bone mass evaluated, and fewer than one-third are treated for osteoporosis. Individual management and a multidisciplinary integrated care plan involving an orthopedist, gerontologist, endocrinologist, physical therapist, occupational therapist, nutritionist, respiratory therapist, physician assistant, and nurse case manager improved adherence to osteoporosis therapy, reduced the risk of falls and subsequent fractures, and reduced postoperative mortality (Table 3 ).

Although educational activities aided in the understanding of patients undergoing hip fracture surgery, the link between education and increased treatment rates was not always clear. Comprehensive treatments, on the other hand, such as these rehabilitation-centered multidisciplinary programs with several experts, were more effective in keeping patients on bone-protecting therapy. As a result, the rates of refracture, falls, and mortality were reduced. Previous research has revealed that $50 \%$ of individuals who have hip fracture surgery do not fully restore their pre-operation function. ${ }^{18}$ In addition to in-hospital acute rehabilitation, many patients require a post-acute care plan that includes continuous active therapy, not only to improve their mobility rapidly but also to successfully 
Table 3 The I-HOPE Program's Multidisciplinary Care Profile

\begin{tabular}{|c|c|c|}
\hline Timepoint (Place) & Intervention & Staff \\
\hline $\begin{array}{l}\text { Admission (to a ward or an } \\
\text { operating room) }\end{array}$ & Survey conducted prior to the operation & $\begin{array}{l}\text { Physician assistant/ } \\
\text { Orthopedist }\end{array}$ \\
\hline \multirow[t]{5}{*}{$\begin{array}{l}3-5 \text { days following surgery } \\
\text { (inpatient department) }\end{array}$} & $\begin{array}{l}\text { Evaluation of the patient's home care requirements. } \\
\text { Pain scale evaluation. }\end{array}$ & $\begin{array}{l}\text { Nurse case } \\
\text { manager }\end{array}$ \\
\hline & $\begin{array}{l}\text { Exercise instruction (ankle pumping, quadriceps, gluteal clamping, straight leg lifting, } \\
\text { and hip adduction/abduction) at the bedside. } \\
\text { Training at the bedside (turning over in bed, sitting, sit to stand, standing posture, and } \\
\text { balance training). } \\
\text { Using a Walker ( } 10-20 \text { meters). } \\
\text { Remind patients who have had hemiarthroplasty not to flex the hip more than } 90 \\
\text { degrees, adduct, or externally rotate. } \\
\text { Patient education to improve home safety and avoid falling again. }\end{array}$ & Physical therapist \\
\hline & $\begin{array}{l}\text { Make loans for assistive equipment and teach people how to utilize them. } \\
\text { Conduct a home environment survey and provide recommendations for changes. }\end{array}$ & $\begin{array}{l}\text { Occupational } \\
\text { therapist }\end{array}$ \\
\hline & Educate patients on proper diet and calcium and vitamin D sources. & Nutritionist \\
\hline & If clinically necessary, physical treatment for the chest and breathing exercises. & $\begin{array}{l}\text { Respiratory } \\
\text { therapist }\end{array}$ \\
\hline \multirow[t]{3}{*}{$\begin{array}{l}7 \text { days after surgery (outpatient } \\
\text { department) }\end{array}$} & $\begin{array}{l}\text { Physical activity, balance, and gait analysis. } \\
\text { Improve training for fragile individuals (CFS }>5 \text { ). } \\
\text { Stress the significance of fall prevention. }\end{array}$ & $\begin{array}{l}\text { Physical therapist } \\
\text { Gerontologist }\end{array}$ \\
\hline & ADL and IADL evaluation. & $\begin{array}{l}\text { Nurse case } \\
\text { manager }\end{array}$ \\
\hline & $\begin{array}{l}\text { Determine the extent of wound healing and mobility range. } \\
\text { DXA scans are used to evaluate bone mineral density. } \\
\text { Begin pharmacologic treatment if osteoporosis is indicated. }\end{array}$ & $\begin{array}{l}\text { Orthopedist/ } \\
\text { Endocrinologist }\end{array}$ \\
\hline \multirow[t]{3}{*}{$\begin{array}{l}\text { I month after surgery (individual } \\
\text { patient's home) }\end{array}$} & $\begin{array}{l}\text { Make the house a safer place to live to reduce the chance of falls. } \\
\text { Instruct the patients to engage in fall prevention activities. } \\
\text { Functional scores are used to evaluate physical activity, balance, and gait (EMS and } \\
\text { POMA). } \\
\text { Adjust the active rehabilitation strategy and ensure adherence. }\end{array}$ & $\begin{array}{l}\text { Physical therapist } \\
\text { Gerontologist }\end{array}$ \\
\hline & $\begin{array}{l}\text { GDS, ADL, and IADL evaluation. } \\
\text { Counsel and educate patients on drug usage and therapy adherence. }\end{array}$ & $\begin{array}{l}\text { Nurse case } \\
\text { manager } \\
\text { Gerontologist }\end{array}$ \\
\hline & Provide dietary evaluation and counseling & Nutritionist \\
\hline \multirow[t]{3}{*}{$\begin{array}{l}6 \text { months after surgery } \\
\text { (outpatient department) }\end{array}$} & $\begin{array}{l}\text { Physical activity, balance, and gait analysis (EMS and POMA). } \\
\text { Instruct the patients to maintain their fall prevention measures. }\end{array}$ & $\begin{array}{l}\text { Physical therapist } \\
\text { Gerontologist }\end{array}$ \\
\hline & GDS, ADL, and IADL evaluation. & $\begin{array}{l}\text { Nurse case } \\
\text { manager }\end{array}$ \\
\hline & Confirm current therapy adherence and reaction. & $\begin{array}{l}\text { Orthopedist/ } \\
\text { Endocrinologist }\end{array}$ \\
\hline
\end{tabular}

Abbreviations: ADL, activities of daily living; CFS, Clinical Frailty Scale; DXA, dual-energy X-ray absorptiometry; EMS, Elderly Mobility Scale; GDS, Geriatric Depression Scale; IADL, instrumental activities of daily living; i-HOPE, the Integrated Hip Fracture and Osteoporosis Rehabilitation Program of the Elderly; POMA, Tinetti Performance Oriented Mobility Assessment. 
regain their functionality. ${ }^{22,23}$ This is the primary reason why a rehabilitation-based strategy was chosen as the foundation of a multidisciplinary care program to enhance patients' functional activities following surgery. This study relied heavily on physical and occupational therapists. Physical therapists were in charge of patients' daily exercise training, while occupational therapists assessed home settings to ensure patients could move safely. During their hospitalization, patients received physical and occupational therapy, which included gait retraining, quadriceps strength training, weight loading exercises, and electrical stimulation of the quadriceps nerves and muscles. The post-surgery rehabilitation regimen includes aerobic and progressive resistance training, muscular strength development, and home rehabilitation.

Furthermore, this rehabilitation-centered cohesive approach would aid in the reduction of care fragmentation. We believe that having a specialized coordinator (nurse case manager) is critical to improving patient identification and supervision (Table 3). A nurse case manager coordinated the home visit intervention following surgery in this supervised program, bringing in additional specialists such as a physical therapist and a nutritionist to provide a complete assessment at home. As predicted, the home visit can assist participants in avoiding additional falls and achieving daily life independence. A handle and a non-slip floor, for example, would be advised to prevent falls in a restroom. A nutritionist might also develop a customized strategy for the elderly to enhance their nutritional condition and avoid postoperative muscle loss. Previous studies discovered that patients with a hip fracture who got structured holistic treatment rather than merely traditional care had a significant reduction in in-hospital mortality, severe comorbidities, and inpatient stay. ${ }^{24-26}$ Similarly, other studies discovered that the fast-track treatment program, which included preoperative health education, early postoperative feeding, and pain relief methods, as well as oxygen therapy, resulted in a significant reduction in postoperative complications (such as pneumonia, delirium, and urinary tract infections) and mortality rate. ${ }^{27-30}$

A previous study discovered that the 1-year death rate of patients treated in an elderly hip fracture program is about $21.2 \%{ }^{28}$ Even while traditional fracture liaison services have the potential to minimize disease burden and associated expenses, there are still logistical problems connected with acquiring sufficient people and material resources. Non-compliance with the care program, for example, or non-adherence to osteoporosis medication, is challenging. Instead, this study's multidisciplinary care program has been shown to effectively increase medication and rehabilitation adherence in patients with fragility hip fractures. Remarkably, the rehabilitationbased multidisciplinary care model's considerable improvement in fall rates may have contributed to the significant reduction in refracture rate and mortality rate of participants in the i-HOPE group. To our knowledge, the i-HOPE multidisciplinary care plan is the most successful strategy in Taiwan for reducing refractures and postoperative mortality in patients with fragility hip fractures.

\section{Conclusion}

We demonstrated that a multidisciplinary approach with supervised osteoporosis therapy and rehabilitation-based services can improve daily function, lower the risk of recurrent falls and fractures, and significantly reduce postoperative mortality in older patients with a fragility hip fracture.

\section{Acknowledgments}

The authors would like to thank Ta-Feng Ho, Cheng-Yu Chang, Tso-Yen Mao, De-Yen Liu, Su-Shun Lo, and Kuan-Hung Lin for their assistance with administrative chores. This study received no particular support from governmental, commercial, or not-for-profit funding organizations.

\section{Disclosure}

The authors report no conflicts of interest in this work.

\section{References}

1. Harvey NC, McCloskey EV, Mitchell PJ, et al. Mind the (treatment) gap: a global perspective on current and future strategies for prevention of fragility fractures. Osteoporos Int. 2017;28:1507-1529. doi:10.1007/s00198-016-3894-y

2. Curtis EM, van der Velde R, Moon RJ, et al. Epidemiology of fractures in the United Kingdom 1988-2012: variation with age, sex, geography, ethnicity and socioeconomic status. Bone. 2016;87:19-26. doi:10.1016/j.bone.2016.03.006

3. Center JR, Bliuc D, Nguyen TV, Eisman JA. Risk of subsequent fracture after low-trauma fracture in men and women. JAMA. 2007;297(4):387-394. doi:10.1001/jama.297.4.387

4. Hsiao PC, Chen TJ, Li CY, et al. Risk factors and incidence of repeat osteoporotic fractures among the elderly in Taiwan: a population-based cohort study. Medicine. 2015;94(7):e532. doi:10.1097/ MD.0000000000000532

5. LeBlanc KE, Muncie HL Jr, LeBlanc LL. Hip fracture: diagnosis, treatment, and secondary prevention. Am Fam Physician. 2014;89:945-951. 
6. Yoo JI, Lee YK, Koo KH, Park YJ, Ha YC. Concerns for older adult patients with acute hip fracture. Yonsei Med J. 2018;59:1240-1244. doi:10.3349/ymj.2018.59.10.1240

7. Oliveira A, Vaz C. The role of sarcopenia in the risk of osteoporotic hip fracture. Clin Rheumatol. 2015;34:1673-1680. doi:10.1007/ s10067-015-2943-9

8. Shen SH, Huang KC, Tsai YH, et al. Risk analysis for second hip fracture in patients after hip fracture surgery: a nationwide population-based study. J Am Med Dir Assoc. 2014;15:725-731. doi:10.1016/j.jamda.2014.05.010

9. Eekman DA, van Helden SH, Huisman AM, et al. Optimizing fracture prevention: the fracture liaison service, an observational study. Osteoporos Int. 2014;25:701-709. doi:10.1007/s00198-013-2481-8

10. Diem SJ, Harrison SL, Haney E, et al. Depressive symptoms and rates of bone loss at the hip in older men. Osteoporos Int. 2013;24 (1):111-119. doi:10.1007/s00198-012-1975-0

11. Perna S, Francis MD, Bologna C, et al. Performance of Edmonton Frail Scale on frailty assessment: its association with multi-dimensional geriatric conditions assessed with specific screening tools. BMC Geriatr. 2017;17(1):2. doi:10.1186/s12877-016-03823

12. Smith R. Validation and reliability of the Elderly Mobility Scale. Physiotherapy. 1994;80:744-747. doi:10.1016/S0031-9406(10) 60612-8

13. Babiuch AS, Oestervemb K, Lipińska A, et al. Differences in the level of physical fitness and mobility among older women with osteoporosis and healthy women-cross-sectional study. Sci Rep. 2021;11(1):14179. doi:10.1038/s41598-021-93483-3

14. Fernandez MA, Griffin XL, Costa ML. Management of hip fracture. Br Med Bull. 2015;115:165-172. doi:10.1093/bmb/ldv036

15. Kung AW, Fan T, Xu L, Xia WB, Park IH, Kim HS. Factors influencing diagnosis and treatment of osteoporosis after a fragility fracture among postmenopausal women in Asian countries: a retrospective study. BMC Women's Health. 2013;13:7. doi:10.1186/1472-6874-13-7

16. Kanis JA, Oden A, McCloskey EV, Johansson H, Wahl DA, Cooper C. A systematic review of hip fracture incidence and probability of fracture worldwide. Osteoporos Int. 2012;23:2239-2256. doi:10.1007/s00198-012-1964-3

17. Lin ZZ, Wang JJ, Chung CR. Epidemiology and mortality of hip fracture among patients on dialysis: Taiwan National Cohort Study. Bone. 2014;64:235-239. doi:10.1016/j.bone.2014.04.017

18. Carpintero P, Caeiro JR, Carpintero R, Morales A, Silva S, Mesa M. Complications of hip fractures: a review. World J Orthop. 2014;5:402-411. doi:10.5312/wjo.v5.i4.402
19. Lin YC, Pan WH. Bone mineral density in adults in Taiwan: results of the Nutrition and Health Survey in Taiwan 2005-2008 (NAHSIT 2005-2008). Asia Pac J Clin Nutr. 2011;20:283-291.

20. Barcenilla-Wong AL, Chen JS, March LM. Concern and risk perception of osteoporosis and fracture among post-menopausal Australian women: results from the Global Longitudinal Study of Osteoporosis in Women (GLOW) cohort. Arch Osteoporos. 2013;8:155. doi:10.1007/s11657-013-0155-y

21. Giangregorio L, Thabane L, Cranney A, et al. Osteoporosis knowledge among individuals with recent fragility fracture. Orthop Nurs. 2010;29:99-107. doi:10.1097/NOR.0b013e3181d2436c

22. Gimigliano F, Iolascon G, Riccio I, et al. Post-surgical rehabilitative approach to fragility fractures. Aging Clin Exp Res. 2013;25(Suppl 1):S23-25. doi:10.1007/s40520-013-0094-X

23. Peeters CM, Visser E, Van de Ree CL, Gosens T, Den Oudsten BL, De Vries J. Quality of life after hip fracture in the elderly: a systematic literature review. Injury. 2016;47:1369-1382. doi:10.1016/j.injury.2016.04.018

24. Vidan MT, Sanchez E, Gracia Y, Maranon E, Vaquero J, Serra JA. Causes and effects of surgical delay in patients with hip fracture: a cohort study. Ann Intern Med. 2011;155:226-233. doi:10.7326/ 0003-4819-155-4-201108160-00006

25. Boddaert J, Cohen-Bittan J, Khiami F. Postoperative admission to a dedicated geriatric unit decreases mortality in elderly patients with hip fracture. PLoS One. 2014;9:e83795. doi:10.1371/journal. pone.0083795

26. Asplin G, Carlsson G, Zidén L, Kjellby-Wendt G. Early coordinated rehabilitation in acute phase after hip fracture - a model for increased patient participation. BMC Geriatr. 2017;17:240. doi:10.1186/ s12877-017-0640-z

27. Binder EF, Brown M, Sinacore DR, Steger-May K, Yarasheski KE, Schechtman KB. Effects of extended outpatient rehabilitation after hip fracture: a randomized controlled trial. JAMA. 2004;292:837-846. doi:10.1001/jama.292.7.837

28. Schnell S, Friedman SM, Mendelson DA, Bingham KW, Kates SL. The 1-year mortality of patients treated in a hip fracture program for elders. Geriatr Orthop Surg Rehabil. 2010;1(1):6-14. doi:10.1177/ 2151458510378105

29. Latham NK, Harris BA, Bean JF, et al. Effect of a home-based exercise program on functional recovery following rehabilitation after hip fracture: a randomized clinical trial. JAMA. 2014;311:700-708. doi:10.1001/jama.2014.469

30. Pedersen SJ, Borgbjerg FM, Schousboe B. A comprehensive hip fracture program reduces complication rates and mortality. $J \mathrm{Am}$ Geriatr Soc. 2008;56:1831-1838. doi:10.1111/j.15325415.2008.01945.x
Journal of Multidisciplinary Healthcare

\section{Publish your work in this journal}

The Journal of Multidisciplinary Healthcare is an international, peerreviewed open-access journal that aims to represent and publish research in healthcare areas delivered by practitioners of different disciplines. This includes studies and reviews conducted by multidisciplinary teams as well as research which evaluates the results or conduct of such teams or healthcare processes in general. The journal covers a very wide range of areas and welcomes submissions from practitioners at all levels, from all over the world. The manuscript management system is completely online and includes a very quick and fair peer-review system. Visit http://www.dovepress.com/testimonials. php to read real quotes from published authors. 